\title{
Modeling, Validation, and Control of Electronically Actuated Pitman Arm Steering for Armored Vehicle
}

\author{
Vimal Rau Aparow, Khisbullah Hudha, Zulkiffli Abd Kadir, \\ Megat Mohamad Hamdan Megat Ahmad, and Shohaimi Abdullah
}

Department of Mechanical Engineering, Faculty of Engineering, National Defense University of Malaysia (NDUM), Kem Sungai Besi, 57000 Kuala Lumpur, Malaysia

Correspondence should be addressed to Vimal Rau Aparow; vimalrau87vb@gmail.com

Received 24 October 2015; Revised 5 March 2016; Accepted 14 March 2016

Academic Editor: Radu Danescu

Copyright (C) 2016 Vimal Rau Aparow et al. This is an open access article distributed under the Creative Commons Attribution License, which permits unrestricted use, distribution, and reproduction in any medium, provided the original work is properly cited.

\begin{abstract}
In this study, 2 DOF mathematical models of Pitman arm steering system are derived using Newton's law of motion and modeled in MATLAB/SIMULINK software. The developed steering model is included with a DC motor model which is directly attached to the steering column. The Pitman arm steering model is then validated with actual Pitman arm steering test rig using various lateral inputs such as double lane change, step steer, and slalom test. Meanwhile, a position tracking control method has been used in order to evaluate the effectiveness of the validated model to be implemented in active safety system of a heavy vehicle. The similar method has been used to test the actual Pitman arm steering mechanism using hardware-in-the-loop simulation (HILS) technique. Additional friction compensation is added in the HILS technique in order to minimize the frictional effects that occur in the mechanical configuration of the DC motor and Pitman arm steering. The performance of the electronically actuated Pitman arm steering system can be used to develop a firing-on-the-move actuator (FOMA) for an armored vehicle. The FOMA can be used as an active safety system to reject unwanted yaw motion due to the firing force.
\end{abstract}

\section{Introduction}

Recently, automotive researchers have focused their work on the advanced technology of steering system to increase the safety system of a vehicle [1-3]. However, most of the advanced researches are mainly concentrated in a passenger vehicle. A number of researches have been carried out in the development of active safety system using rack and pinion steering configuration. An active front wheel steering system using rack and pinion configuration has been developed by automotive developers, BMW [4]. This invention allows driver-independent steering system by intervening at the front axle using the mechanical link between the steering wheel and the front axle. The system is supported with double planetary gear and an actuated DC motor. Meanwhile, other researchers also actively involved in implementation of the active front wheel steering system as a vehicle yaw stability control method [5]. This method has been used to reject the unwanted yaw motion due to aerodynamic disturbance. The similar type of active steering has been used in the development of direct yaw moment control and also advanced driver support technology [6].

Steering system using rack and pinion configuration also has been used to develop electric power assisted system (EPAS) for passenger vehicle [7]. The EPAS has been used to design an active disturbance rejection control to reduce the steering torque exerted by the driver due to external side wind force. Other automotive researchers as stated in $[8,9]$ focused on the safety system of steering system using steerby-wire technology. This technology is mainly invented from an aircraft system known as fly-by-wire. Besides, there are also some studies related to hardware-in-the-loop simulation (HILS) to investigate the performance of the active front wheel steering to develop yaw rejection control system using rack and pinion test rig [10-12]. However, most of the previous work is mainly related to rack and pinion type of steering system which is basically implemented in a passenger vehicle. 
Meanwhile, research works related on the Pitman arm steering system are very much limited. Commercial heavy vehicle research in California has initiated research on the safety performance of heavy vehicle system using an actual truck [13]. The research entirely focuses on the modeling, development of heavy vehicle using ADAMS software, and validation with an actual vehicle. However, the validation on Pitman arm steering is not included in this work. Recently, an active independent front steering (AIFS) has been developed to compare with the conventional active front wheel steering system [14]. This active system used the truck model to develop active independent front steering system but has neglected the Pitman arm steering model. Thus, it clearly shows that most of the automotive researchers have not considered the performance evaluation of the Pitman arm steering system before it can be implemented in virtual or actual heavy vehicle system.

To overcome the limitations of active safety system in heavy vehicle technology due to the steering mechanism, a detailed investigation on the Pitman arm steering system is required in this study. A detailed modeling related to the Pitman arm steering system is developed with additional DC motor. The developed model is compared using an actual Pitman arm steering system to validate the behavior of developed model. In order to evaluate the capability of the Pitman arm steering for the active safety system, position tracking response is used in this study. The position tracking response is tested using the validated Pitman arm steering model via simulation. Then, the same tracking response has been implemented in the actual Pitman steering system using hardware-in-the-loop simulation (HILS) technique with additional friction compensation using Karnopp model. The control parameters from simulation or named as software-in-the-loop simulation (SILS) is used as benchmark control parameters in HILS testing.

This paper is organized as follows: Section 1 contains introduction, review on other research works, and review on the design and performance evaluation using steering system. Section 2 introduces detailed mathematical derivation of Pitman arm steering system using MATLAB/SIMULINK software. Section 3 discusses the validation of the developed Pitman arm steering model using actual Pitman arm steering test rig. Section 4 focuses on the position tracking response of both validated and actual Pitman arm steering system. Simulation method is used to evaluate the effectiveness of the validated steering model. Meanwhile, hardware-in-theloop simulation (HILS) technique is used to investigate the position tracking control analysis in real environment. Section 6 explains the potential applications of the active Pitman arm steering system as firing-on-the-move actuator and finally the conclusion.

\section{Modeling of Pitman Arm Steering Actuated by DC Motor Model}

Pitman arm steering system is commonly used in wheeled armored vehicle. Thus, a multi-DOF Pitman arm steering model is developed using Newton's second law of motion as shown in Figure 1 which consists of steering wheel and

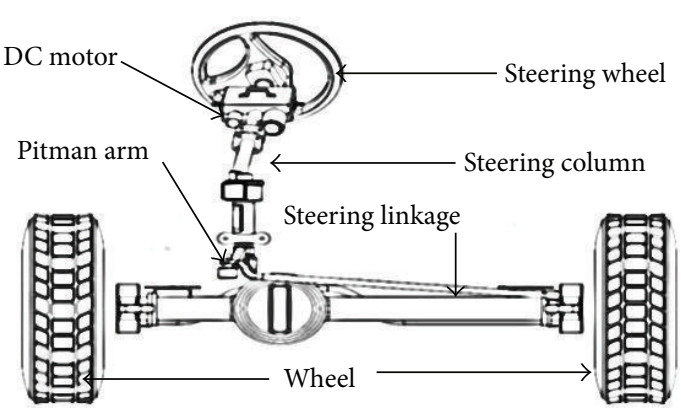

Figure 1: Pitman arm steering system.

column, Pitman arm link, hydraulic assist, steering linkage, and wheel itself.

An additional torque from DC motor is included in the steering model to improve performance of conventional Pitman arm steering mechanism for active front wheel steering (AFWS).

2.1. Steering Column Equation. By assuming the rotation of the steering wheel is equivalent to the rotational motion of the steering wheel, the following equation is formulated as follows:

$$
\begin{aligned}
& J_{\mathrm{eq}} \ddot{\theta}_{\mathrm{eq}}+B_{\mathrm{eq}} \dot{\theta}_{\mathrm{eq}}+K_{\mathrm{sc}} \theta_{\mathrm{eq}} \\
& \quad=T_{\mathrm{DC}}+T_{\mathrm{HP}}-T_{\mathrm{PA}}-F_{\mathrm{C}} \operatorname{sign} \dot{\theta}_{\mathrm{eq}},
\end{aligned}
$$

where

$$
\begin{aligned}
& J_{\mathrm{eq}}=J_{\mathrm{sc}}+\left(N_{1}^{2} \times J_{m}\right), \\
& B_{\mathrm{eq}}=B_{\mathrm{sc}}+\left(N_{1} \times B_{m}\right) \\
& \theta_{\mathrm{eq}}=\theta_{\mathrm{sc}}-\theta_{\mathrm{sw}},
\end{aligned}
$$

where $J_{\text {sc }}$ and $J_{m}$ are moments of inertia of steering column and $\mathrm{DC}$ motor and $T_{\mathrm{HP}}, T_{\mathrm{DC}}$, and $T_{\mathrm{PA}}$ are torque due to hydraulic assisted pump, DC motor, and Pitman arm member link. Meanwhile, $B_{\mathrm{sc}}$ and $B_{m}$ are defined as viscous damping of steering column and DC motor. $F_{c}$ are known as steering column friction while $\theta_{k}, \theta_{\mathrm{sc}}$, and $\theta_{\mathrm{sw}}$ are angular displacement due to universal joint, steering column, and steering wheel.

2.2. Equation of DC Motor. Basically, the DC motor is modeled by considering electrical and mechanical parts as shown in Figure 2. Based on Kirchhoff Voltage Law (KVL), the total voltage for the electrical part can be obtained as

$$
\begin{aligned}
& e_{m}=\left(R_{a} \times I_{a}\right)+\left(L_{a} \times \dot{I}_{a} \times N_{1}\right)+e_{b}, \\
& e_{b}=\left(K_{b} \times \dot{\theta}_{s c}\right) \times N_{1} .
\end{aligned}
$$

The motor torque, $T_{\mathrm{DC}}$, can be formulated as

$$
T_{\mathrm{DC}}=K_{t} \times I_{a} \times N_{1},
$$




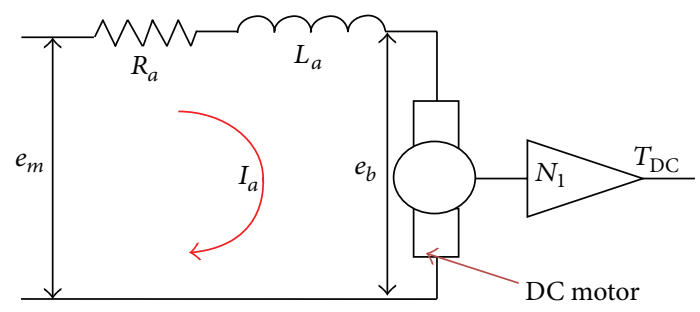

FIGURE 2: Electrical and mechanical model of DC motor.

where $e_{m}$ is the DC motor input voltage, $e_{b}$ is back electromagnetic force, and $R_{a}, L_{a}$, and $I_{a}$ are the resistor, inductance, and current flow of the DC motor. The terms $K_{b}$ and $K_{t}$ are defined as back electromagnetic force and motor torque constants and $N_{1}$ is defined as DC motor gear ratio. Rearrange expression (5) as a function of $I_{a}$ as

$$
I_{a}=\frac{T_{\mathrm{DC}}}{\left(K_{t} \times N_{1}\right)} .
$$

By substituting expression (6) into (3), the final equation for DC motor's torque can be obtained as

$$
\begin{aligned}
& T_{\mathrm{DC}} \\
& =\frac{K_{t} \times N_{1}}{\left(R_{a}\right)}\left[e_{m}-\left(K_{b} \times \dot{\theta}_{\mathrm{sc}} \times N_{1}\right)+\left(L_{a} \times \dot{I}_{a} \times N_{1}\right)\right],
\end{aligned}
$$

where $R_{a}$ is $0.1 \mathrm{ohm}, L_{a}$ is $0.0001 \mathrm{H}, N_{1}$ is $16: 3$ gear ratio, and $K_{b}$ is $0.0533 \mathrm{~N} \cdot \mathrm{m} / \mathrm{A}$.

2.3. Hydraulic Power Assisted Equation. The other mechanism connected to the steering column is the hydraulic power assisted unit. This unit enables elimination of extensive modifications to the existing steering system and reduces effort by the driver to rotate the steering wheel since the hydraulic power assisted unit is able to produce large steering effort using hydraulic pump, rotary spool valve, and Pitman arm:

$$
T_{\mathrm{HP}}=l \times A_{p} \times \int\left(\frac{d P_{l}}{d t}-\frac{d P_{r}}{d t}\right),
$$

where $P_{r}$ and $P_{l}$ are right and left cylinder pressures, while $l$ is defined as length of cylinder and the piston area of the cylinder is expressed as $A_{p}$. The detailed description can be obtained from [15].

2.4. Universal Joint Equation. Due to the limitation of space at the engine location of the armored vehicle, the hydraulic power assisted system cannot be located at the same axis as the steering wheel. Hence, an additional join known as universal joint is used as a solution to overcome the space constraint. The universal joint angle is used for the steering mechanism since it is a flexible coupling where it is rigid in torsion but compliant in bending. The angle of $\emptyset$ is set at 20 degrees lower than the steering column, $\theta_{\text {sc }}[16]$, and described as

$$
\theta_{k}=\tan ^{-1}\left(\frac{\tan \theta_{\text {sc }}}{\cos \emptyset}\right)
$$

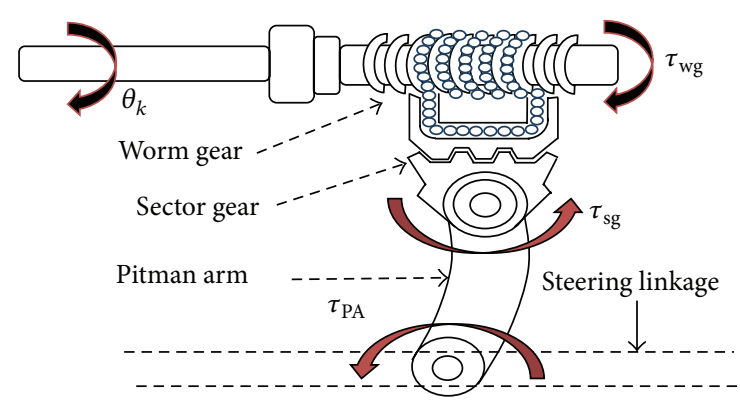

Figure 3: System configuration using Pitman arm.

2.5. Description on Pitman Arm. The torque from the hydraulic power assisted model is transferred to actuate the Pitman arm member link through the worm and sector gears. The Pitman arm converts the rotational motion of the steering column into translational motion at the steering linkage. The configuration of worm gear, sector gear, and the Pitman arm member is shown in Figure 3. Based on Figure 3 , the output torque of the Pitman arm link, $T_{\mathrm{PA}}$, can be obtained by equating both worm and sector gear torque, $T_{\mathrm{wg}}$ and $T_{\mathrm{sg}}$, as

$$
T_{\mathrm{sg}}=\eta_{\mathrm{sg}} \times T_{\mathrm{wg}}=\eta_{\mathrm{sg}} \times\left[K_{\mathrm{tr}}\left(\theta_{k}-\theta_{\mathrm{wg}}\right)\right]
$$

where ratio of sector gear is $\eta_{s g}$ and $\theta_{\mathrm{wg}}$ is the angular displacement of worm gear. Since the torque created at sector gear is equal to the torque created at the end joint of Pitman arm, hence

$$
T_{\mathrm{sg}}=T_{\mathrm{PA}} .
$$

2.6. Steering Linkage Equation. The rotational input from the sector gear is converted into translational motion to the steering linkage using Pitman arm joint link. By using the torque from Pitman arm as the input torque, the equation of motion of the steering linkage is [17]

$$
\begin{aligned}
& M_{L} \ddot{y}_{L}+B_{L} \dot{y}_{L}+\left[C_{\mathrm{SL}} \operatorname{sgn}\left(\dot{y}_{L}\right)\right]-\left[\frac{b_{r} \times T_{\mathrm{PA}}}{M_{L} \times R_{\mathrm{PA}}}\right] \\
& =\eta_{f}\left(\frac{T_{\mathrm{PA}}}{R_{\mathrm{PA}}}\right)-\eta_{B}\left(\frac{T_{\mathrm{KL}}}{N_{M}}\right),
\end{aligned}
$$

where $M_{L}, B_{L}$, and $C_{S L}$ are mass, viscous damping, and coulomb friction breakout force of steering linkage. Additionally, the terms $y_{L}, b_{r}$, and $R_{\mathrm{PA}}$ are the translational displacement, resistance at steering linkage, and radius of Pitman arm. $\eta_{f}$ and $\eta_{B}$ are the gear ratio efficiency of forward and backward transmission. 


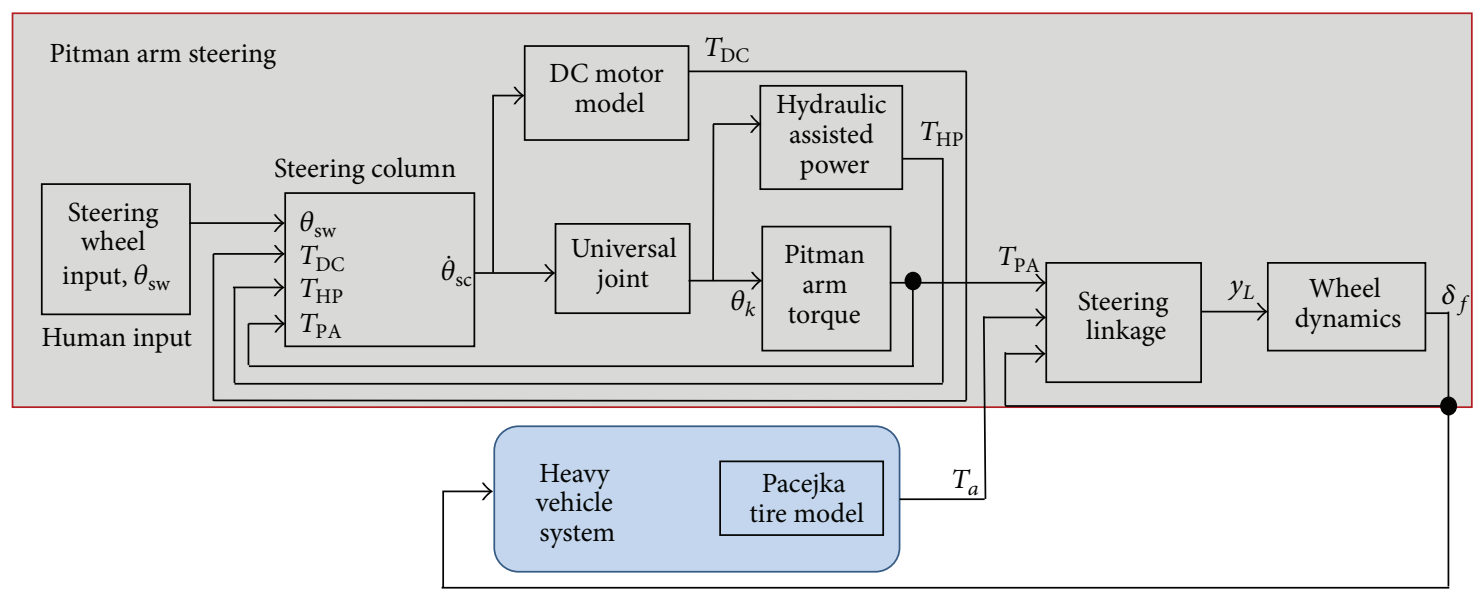

FIGURE 4: Overall configuration of Pitman arm steering system using electronically actuated DC motor.

2.7. Wheel Dynamics Equation. By using (1), (7), (8), and (11), equation of motion of the wheel can be obtained. The output response of the wheel which is wheel angle, $\delta_{f}$, is given by

$$
\begin{aligned}
J_{\mathrm{fw}} & \ddot{\delta}_{f}+B_{\mathrm{fw}} \dot{\delta}_{f}+\left[C_{\mathrm{fw}} \operatorname{sign}\left(\dot{\delta}_{f}\right)\right]+K_{\mathrm{fw}} \delta_{f} \\
= & T_{\mathrm{KL}}+T_{a} \\
T_{\mathrm{KL}} & =K_{\mathrm{SL}}\left(\left(\frac{y_{L}}{N_{M}}\right)-\delta_{f}\right)
\end{aligned}
$$

where $J_{\mathrm{fw}}, B_{\mathrm{fw}}$, and $C_{\mathrm{fw}}$ are the moment of inertia of road wheel and rotation mass about steering displacement, viscous damping of steering linkage bushing, and coulomb friction breakout force on road wheel. $T_{a}$ and $T_{\mathrm{KL}}$ are the tire alignment moment from Pacejka Magic Tire model and torque at steering linkage. $N_{M}, K_{\mathrm{fw}}$, and $K_{\mathrm{SL}}$ are rotational ratio of steering linkage, steering wheel stiffness, and steering translational stiffness due to linkage and bushing. Figure 4 shows overall configuration of the Pitman arm steering actuated by DC motor.

The state space equation is developed to summarize the final equations of the Pitman arm steering system as shown below:

For steering column,

$$
\begin{aligned}
& q_{1}=\theta_{\mathrm{eq}} ; \\
& q_{2}=\dot{\theta}_{\mathrm{eq}} ; \\
& \dot{q}_{1}=\dot{\theta}_{\mathrm{eq}}=q_{2}, \\
& \dot{q}_{2}=\ddot{\theta}_{\mathrm{eq}}=\frac{1}{J_{\mathrm{eq}}}\left[\sum T_{\mathrm{sc}}-\left(B_{\mathrm{eq}}+F_{\mathrm{c}} \mathrm{sgn}\right) \dot{\theta}_{\mathrm{eq}}-K_{\mathrm{sc}} \theta_{\mathrm{eq}}\right], \\
& \dot{\mathbf{q}}=\mathbf{A q}+\mathbf{B} u,
\end{aligned}
$$

$$
\begin{aligned}
& A=\left[\begin{array}{cc}
0 & 1 \\
-\frac{\left(B_{\mathrm{eq}}+F_{c} \operatorname{sign}\right)}{J_{\mathrm{eq}}} & -\frac{K_{\mathrm{sc}}}{J_{\mathrm{eq}}}
\end{array}\right] ; \\
& B=\left[\begin{array}{c}
0 \\
\frac{\sum T_{\mathrm{sc}}}{J_{\mathrm{eq}}}
\end{array}\right],
\end{aligned}
$$

where $\sum T_{\mathrm{sc}}=T_{\mathrm{DC}}+T_{\mathrm{HP}}-T_{\mathrm{PA}}$.

For steering linkage,

$$
\begin{aligned}
& q_{3}=y_{L} \\
& q_{4}=\dot{y}_{L} \text {; } \\
& \dot{q}_{3}=\dot{y}_{L}=q_{4} \text {, } \\
& \dot{q}_{4}=\ddot{y}_{L}=\frac{1}{M_{L}}\left[-\left(B_{L}+C_{S L} \operatorname{sgn}\right) \dot{y}_{L}\right. \\
& -\left(\frac{b_{r} \times T_{\mathrm{PA}}}{M_{L} \times R_{\mathrm{PA}}}\right) \eta_{B}\left(\frac{K_{\mathrm{SL}}\left(\left(1 / N_{M}\right)-\delta_{f}\right)}{N_{M}}\right) y_{L} \\
& \left.+\eta_{f}\left(\frac{T_{\mathrm{PA}}}{R_{\mathrm{PA}}}\right)\right] \\
& \dot{\mathbf{q}}=\mathbf{C q}+\mathbf{D} u, \\
& C=\left[\begin{array}{cc}
0 & 1 \\
-\left(\frac{B_{L}+C_{\mathrm{SL}} \operatorname{sgn}}{M_{L}}\right) & \eta_{B}\left(\frac{K_{\mathrm{SL}}\left(\left(1 / N_{M}\right)-\delta_{f}\right)}{N_{M} \times M_{L}}\right)
\end{array}\right], \\
& D=\left[\begin{array}{c}
0 \\
-\frac{1}{M_{L}}\left[\left(\frac{b_{r} \times T_{\mathrm{PA}}}{M_{L} \times R_{\mathrm{PA}}}\right)+\eta_{f}\left(\frac{T_{\mathrm{PA}}}{R_{\mathrm{PA}}}\right)\right]
\end{array}\right] \text {. }
\end{aligned}
$$




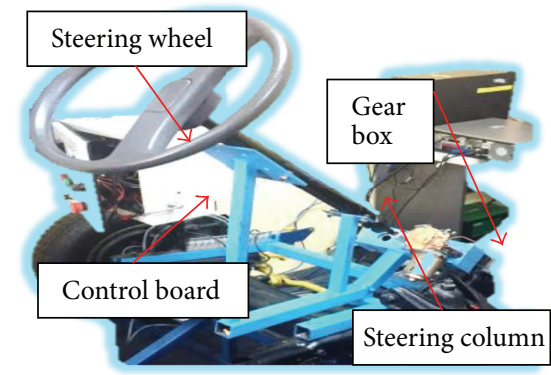

(a) Top part of Pitman arm steering test rig

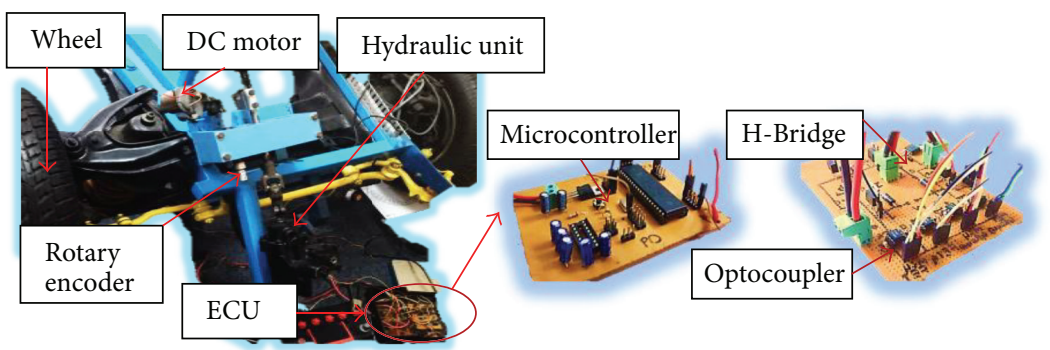

(b) Bottom part of the Pitman arm steering test rig

FIGURE 5: Pitman arm test rig with ECU control system for HILS [18].

For wheel dynamic,

$$
\begin{aligned}
q_{5} & =\delta_{f} ; \\
q_{6} & =\dot{\delta}_{f} ; \\
\dot{q}_{5} & =\dot{\delta}_{f}=q_{6}, \\
\dot{q}_{2} & =\ddot{y}_{L} \\
& =\frac{1}{J_{\mathrm{fw}}}\left[\sum T_{\mathrm{fw}}-\left(B_{\mathrm{fw}}+C_{\mathrm{fw}} \mathrm{sgn}\right) \dot{\delta}_{f}+K_{\mathrm{fw}} \delta_{f}\right], \\
\dot{\mathbf{q}} & =\mathbf{E q}+\mathbf{F u}, \\
E & =\left[\begin{array}{cc}
\frac{-\left(B_{\mathrm{fw}}+C_{\mathrm{fw}} \mathrm{sgn}\right)}{J_{\mathrm{fw}}} & \frac{K_{\mathrm{fw}}}{J_{\mathrm{fw}}}
\end{array}\right] ; \\
F & =\left[\begin{array}{c}
0 \\
\left.\frac{\sum T_{\mathrm{fw}}}{J_{\mathrm{fw}}}\right] .
\end{array}\right.
\end{aligned}
$$

\section{Validation of Pitman Arm Steering Model}

In this section, the behavior of Pitman arm steering model is validated with actual Pitman arm steering system by using hardware-in-the-loop (HIL) technique. The purpose of this validation is to analyze the performance of mathematical model of Pitman arm steering model which is used in heavy vehicle such as truck, bus, or wheeled military vehicle. The parameters of the Pitman arm steering model are listed in Table 1. The performance of the model is validated using three types of lateral inputs such as double lane change, slalom, and step steer test. A detailed discussion on the performance of the Pitman arm steering model is discussed in this section.

3.1. Hardware Setup. A Pitman arm steering test rig has been prepared in Automotive Laboratory at National Defense University of Malaysia (NDUM) as shown in Figure 5. Two incremental rotary encoders are installed at the steering column and wheel chamber. Meanwhile, a DC motor has been attached to the steering column to provide steering inputs as initiated from the host PC. An ECU as shown in

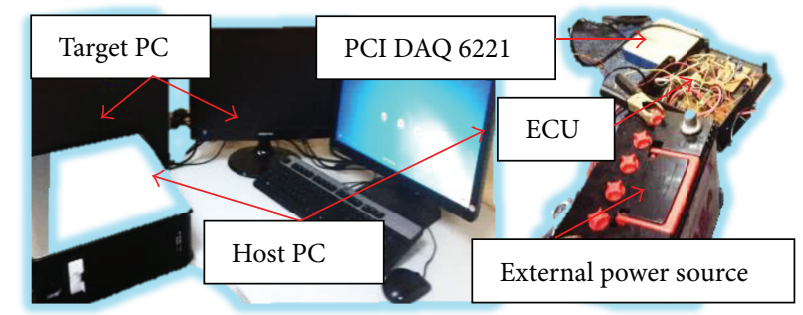

FIGURE 6: Hardware-in-the-loop setup.

Figure 4 has been designed to operate the DC motor using hardware-in-the-loop (HIL) simulation $[18,19]$.

3.2. Hardware-in-the-Loop Setup. HIL technique is used in this study to validate the developed mathematical model of Pitman arm steering model with the actual Pitman arm steering mechanism and to evaluate the performance of the Pitman arm steering by providing various wheel inputs. HIL can be divided into two systems which are software and hardware. Software part includes signal interface between Target PC and HOST PC, xPC Target, and Real-Time Workshop software to control DC motor and measure the signal of rotary encoder while Visual Studio 2012 Express used as a C compiler for xPC Target. MATLAB/SIMULINK software has been used as interface to interlink between the hardware and HOST $\mathrm{PC}$ via $\mathrm{xPC}$ Target. As for the hardware section, it involves with the HOST PC, Target PC, Gear box of DC motor, DC motor, Pitman arm steering test rig, rotary encoders, PCI network card, and data acquisition system, known as National Instrument (NI) board. The configuration of hardware can be observed in Figures 5 and 6 as shown below. With a host computer running xPC Target, MATLAB/SIMULINK, Real-Time Workshop, and a C compiler as the development environment, real-time Pitman arm characteristic can be generated and run on a Target PC using the xPC Target realtime kernel. After the Target PC is interlinked with hardware, the Pitman arm steering can be simulated in real time [18].

3.3. Validation Results. Four types of steering inputs have been used to validate the Pitman arm steering model. The inputs are known as double lane change and slalom test at 
TABLE 1: Parameter of the Pitman arm steering model.

\begin{tabular}{|c|c|c|}
\hline Description & Symbol & Value \\
\hline Moment of inertia of steering wheel & $J_{\mathrm{sw}}$ & $0.035 \mathrm{~kg} \mathrm{~m}^{2}$ \\
\hline Viscous damping of steering wheel & $B_{\mathrm{sw}}$ & $0.36 \mathrm{Nm} /(\mathrm{rad} / \mathrm{sec})$ \\
\hline Steering column rotational stiffness & $K_{\mathrm{sc}}$ & $42000 \mathrm{Nm} / \mathrm{rad}$ \\
\hline Angular displacement due to universal joint & $\theta_{k}$ & $20^{\circ}$ \\
\hline Steering arm length & $l_{s}$ & $0.2 \mathrm{~m}$ \\
\hline Return pressure & $P_{o}$ & $0 \mathrm{~N} / \mathrm{m}^{2}$ \\
\hline Pump flow rate & $\mathrm{Q}_{s}$ & $0.0002 \mathrm{~m}^{3} / \mathrm{s}$ \\
\hline Piston area & $A_{p}$ & $0.005 \mathrm{~m}^{2}$ \\
\hline Cylinder length & $L$ & $0.15 \mathrm{~m}$ \\
\hline Orifice flow coefficient & $C_{\text {do }}$ & 0.6 \\
\hline Fluid density & $\rho$ & $825 \mathrm{~kg} / \mathrm{m}^{3}$ \\
\hline Fluid volume & $V_{s}$ & $8.2 \times 10^{-5} \mathrm{~m}^{3}$ \\
\hline Fluid bulk modulus & $\beta_{f}$ & $7.5 \times 10^{8} \mathrm{~N} / \mathrm{m}^{2}$ \\
\hline Torsion bar rotational stiffness & $K_{\text {tr }}$ & $35000 \mathrm{Nm} / \mathrm{rad}$ \\
\hline Sector gear ratio & $\tau_{\text {sg }}$ & 0.5 \\
\hline Moment of inertia of steering column & $J_{\mathrm{sc}}$ & $0.055 \mathrm{~kg} \mathrm{~m}^{2}$ \\
\hline Viscous damping of steering column & $B_{\mathrm{sc}}$ & $0.26 \mathrm{Nm} /(\mathrm{rad} / \mathrm{sec})$ \\
\hline Coulomb friction breakout force on steering linkage & $C_{\mathrm{SL}}$ & $0.5 \mathrm{~N}$ \\
\hline Gear ratio efficiency of forward transmission & $\eta_{f}$ & 0.985 \\
\hline Gear ratio efficiency of backward transmission & $\eta_{B}$ & 0.985 \\
\hline Steering rotational stiffness due to linkage and bushing & $K_{\mathrm{SL}}$ & $15500 \mathrm{Nm} / \mathrm{rad}$ \\
\hline Metering orifice & $A_{1}$ and $A_{2}$ & $2.5 \mathrm{~mm}^{2}$ \\
\hline
\end{tabular}

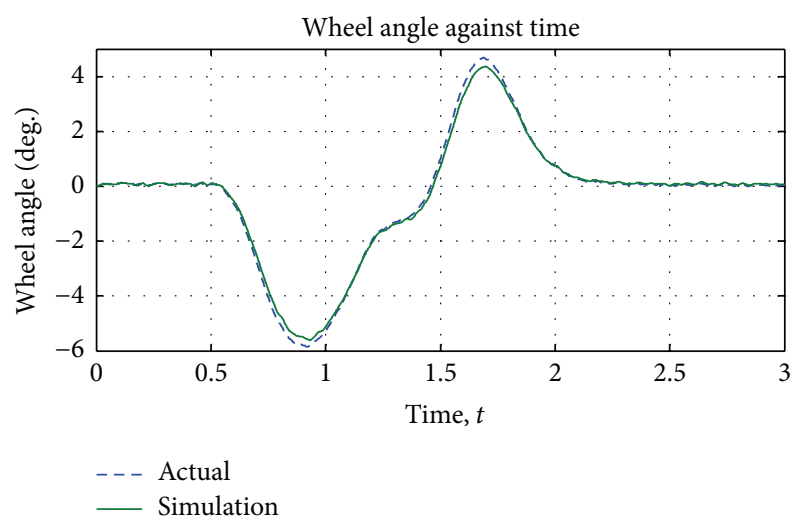

Figure 7: Wheel angle for double lane change case.

90 degrees as well as step steer at 90 and 180 degrees. The validation results are presented in Figures 7-10 which are the comparison between the measured the wheel angle and also the wheel angle from the simulated Pitman arm steering model based on the actual steering inputs. Based on the validation results, it can be concluded that the mathematical model of Pitman arm steering actuated by DC motor model is able to follow the desired response which was obtained from actual steering responses.

In order to analyze the performance of the developed Pitman arm model, the maximum error between actual and

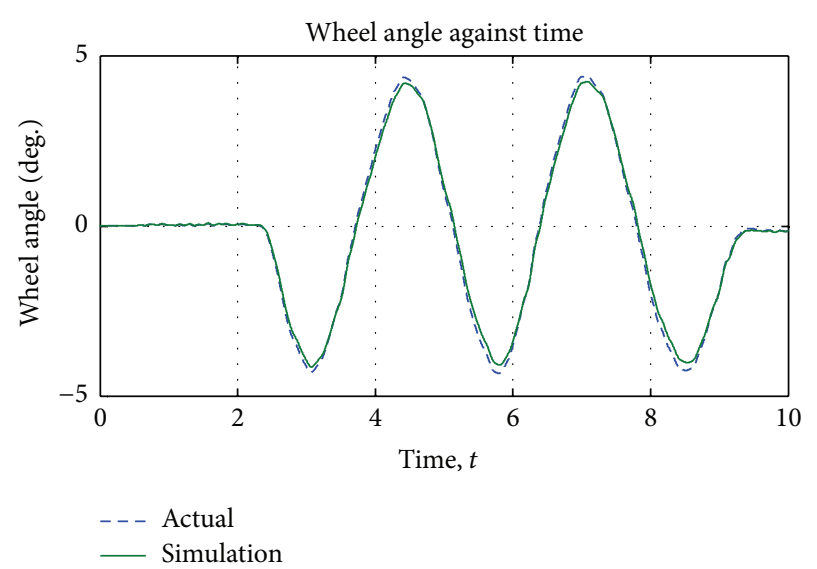

FIGURE 8: Wheel angle for slalom case.

simulation results and root mean square (RMS) is analyzed in this study. The maximum error for double lane change and slalom test is $2.35 \%$ and $1.81 \%$. Meanwhile, the maximum errors for step steer test at both 90 and 180 degrees are $3.23 \%$ and $3.07 \%$. The maximum error range is less than $5 \%$. Similarly, the percentages of RMS value for both simulation and actual Pitman arm steering model are compared. The percentages of differences using RMS value between simulated and actual system are not more than $2 \%$ as shown in Table 2. 


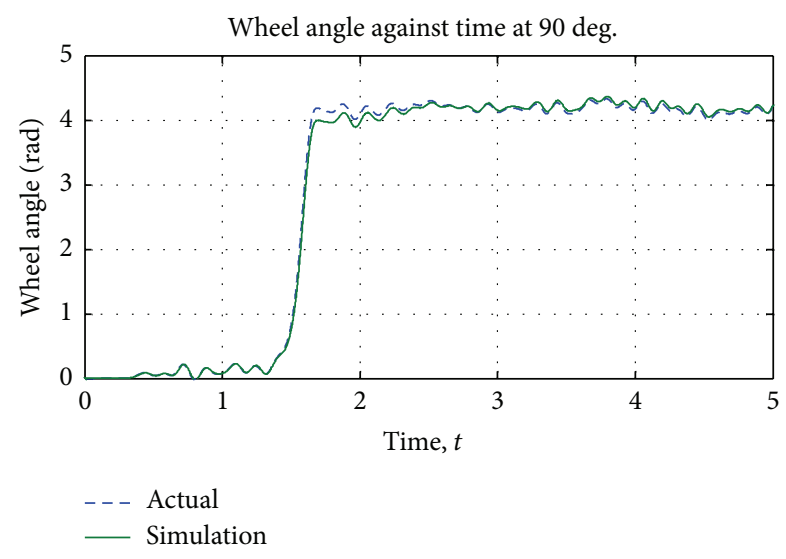

FIGURE 9: Wheel angle of step steer case at 90-degree steering angle.

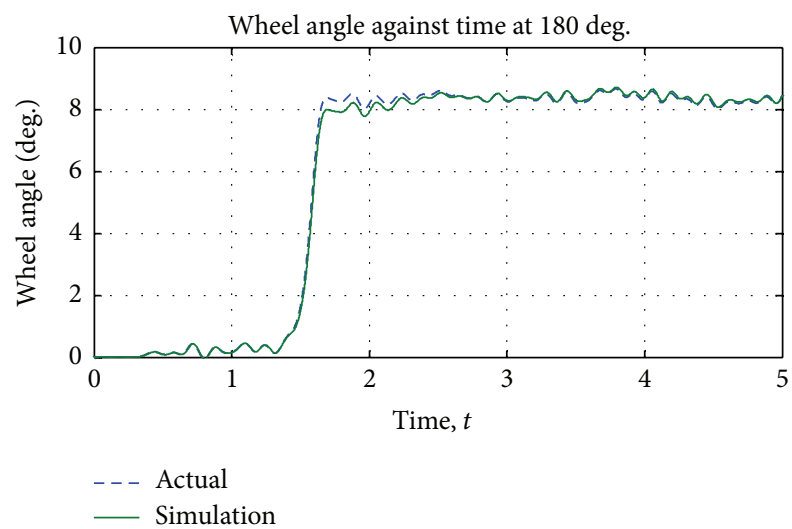

Figure 10: Wheel angle of step steer case at 180-degree steering angle.

TABLE 2: Percentage value of RMS difference.

\begin{tabular}{lccc}
\hline \multirow{2}{*}{ Test } & \multicolumn{2}{c}{ RMS } & Percentage difference (\%) \\
& Actual & Sim & \\
\hline Double lane change & 0.331 & 0.325 & 1.69 \\
Slalom & 0.00253 & 0.00257 & 1.43 \\
Step steer at 90 deg. & 0.0715 & 0.0719 & 0.61 \\
Step steer at 180 deg. & 0.0772 & 0.0778 & 0.78 \\
\hline
\end{tabular}

\section{Hardware-in-the-Loop Simulation of Pitman Arm Steering System}

Before implementing steering mechanism into active safety system of a vehicle such as steer-by-wire, active front wheel steering, and electronic stability control, the mechanism should be tested using hardware-in-the-loop simulation (HILS) technique. HILS testing or commonly known as virtual testing electronic control has also become one of the repository tools for the automotive researchers and designers. HILS technique is required in testing an actuator to identify its capability and performance before it can be applied to any real automotive system.
In this study, both mathematical model and actual Pitman arm steering are tested using various wheel inputs. The mathematical model is tested via simulation known as software-inthe-loop simulation (SILS) analysis by tuning the controller parameters to its optimum value which can be used for various inputs. The parameters of PID controller are tuned by using the Ziegler-Nichols technique. The Ziegler-Nichols tuning method attempts to produce optimum values for the PID gain parameters $[20,21]$. The similar control parameters are implemented while testing the actual pitman arm steering mechanism using HILS technique.

Two types of control loops are mainly focused in position tracking control of the pitman arm steering mechanism which are inner and outer loop control. The inner loop control is focused on the position control of a DC motor for both simulation and HILS technique which can be referred from [19]. Meanwhile, the outer loop control is designed by using the Pitman arm steering model for simulation analysis and actual mechanisms for HIL analysis. A conventional PID control is used as the controller for both inner and outer loop controls.

4.1. Position Tracking Control. The position tracking control is developed by merging both inner and outer loop controls as shown in Figure 11. Two PID controllers have been used to control the DC motor shaft's rotational angle and also the steering column of the Pitman arm steering system. The first PID controller is used to command the DC motor by varying the voltage input to the DC motor. Meanwhile, the second PID controller is used to actuate the steering column according to the desired inputs. Therefore, the validated Pitman arm steering model is used initially to evaluate position tracking control using a PID controller via SILS analysis. The control structure of the position tracking control is developed as shown in Figure 11.

Meanwhile, Figure 12 shows the control structure for position tracking control of the Pitman arm steering model using an automotive DC motor. Two rotary sensors have been used to measure the rotation angle of the DC motor which is attached to the steering column. Meanwhile, the other rotary sensor is mounted at the wheel to measure actual wheel angle. The output signal from first PID controller is sent as analogue output to the DC motor using the PCI 6221 National Instrument (DA). The signals obtained from rotary sensors which are connected through PCI 6221 National Instrument (DA) are used as feedback input to the HILS evaluation. Likewise, the position tracking of the Pitman arm steering system is validated using four different types of inputs, namely, sine, square, sawtooth, and step inputs. Similar PID control parameters from SILS are used for the HILS experiment as the benchmark point. However, there are slight changes in the control parameters due to the frictional force that occurred on the Pitman arm member link and also backlash occurred at the gear mechanism which connects the DC motor and the steering column. The control parameters are listed in Table 3 for further references.

In the HILS results, there are some disturbances that occurred due to the mechanical friction which affects the performance of the Pitman arm steering system. In order to 


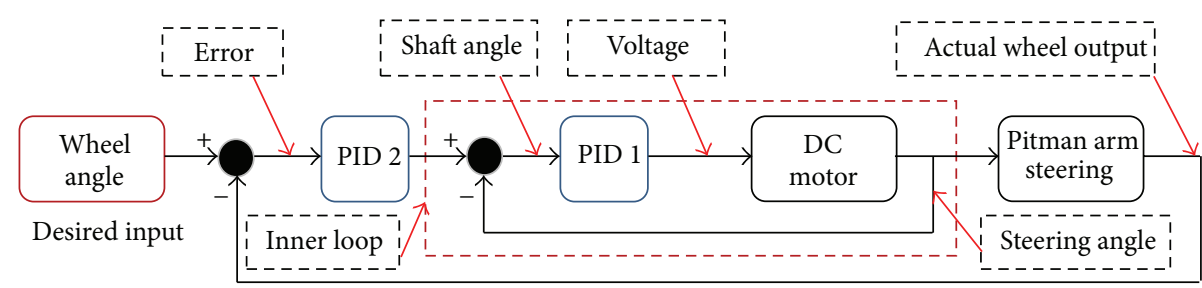

FIGURE 11: Position tracking control using validated steering model for SILS.

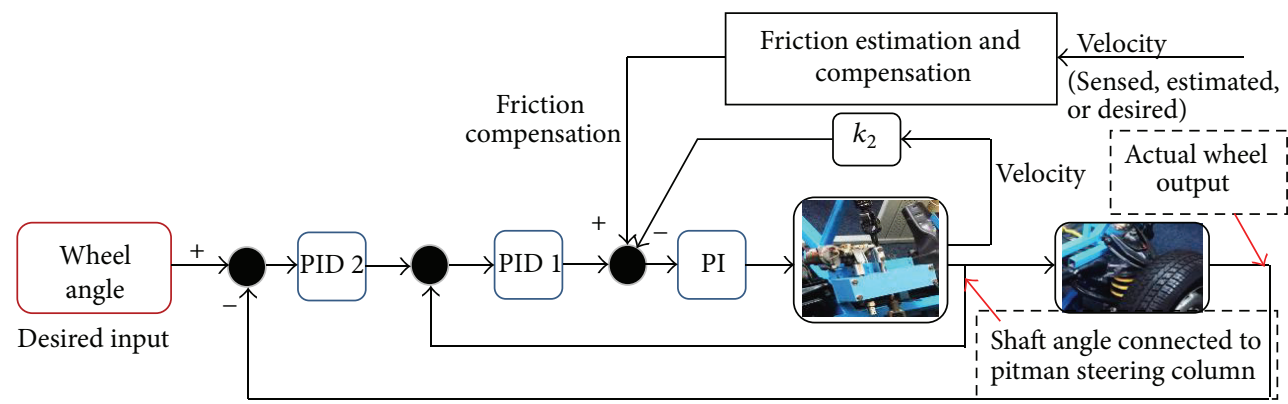

FIGURE 12: Position tracking control using actual Pitman arm steering for HILS.

TABLE 3: Controller parameters for inner and outer loop.

\begin{tabular}{lcccccc}
\hline \multirow{2}{*}{ Technique } & \multicolumn{3}{c}{ Inner loop } & \multicolumn{3}{c}{ Outer loop } \\
& $\mathrm{P}$ & $\mathrm{I}$ & $\mathrm{D}$ & $\mathrm{P}$ & $\mathrm{I}$ & $\mathrm{D}$ \\
\hline SILS & 9.5 & 0.01 & 2.7 & 33 & 2.7 & 0.03 \\
HILS & 15 & 0.01 & 6 & 40 & 0.15 & 0.03 \\
\hline
\end{tabular}

minimize the effect, a model-based compensation approach is used in this study. Its implementation requires choice of an appropriate friction model, identification of its parameters, and finally friction compensation using the identified model. Besides, this model also assumes that the frictional force or torque of adequate bandwidth is available and stiffly coupled to the friction element. Therefore, friction compensation is implemented by adding the opposite of the predicted friction to the control signal as shown in Figure 15. To cope with the presence of actuator dynamics, one possibility is to use an inner force control loop, in addition to the position control loop. The HILS control structure with implementation of friction compensation can be minimized position steady state error and oscillation generated by unwanted friction. In this paper, the diagram in Figure 14 is used for Karnopp modelbased friction compensation in the electric DC motor and Pitman steering system. Model-based friction compensation using the Karnopp model, in an electric-motor system, has been already used [22]. This compensator gives satisfactory results when the objective is position tracking response.

The Karnopp model solves the unwanted friction problem by introducing a pseudo velocity a small neighbourhood of zero velocity, $D_{v}$. The pseudo velocity, $p(t)$, which is referred from momentum, is integrated in the standard way:

$$
\dot{p}(t)=\left[F_{a}(t)-F_{m}(t)\right]
$$

where $F_{a}(t)$ is the force acting on the system while $F_{m}(t)$ is the estimated friction force based on the system response. The velocity of the system is set according to (17) where $M_{\mathrm{fc}}$ is referred to as steering mass:

$$
v(t)= \begin{cases}0 & |p(t)|<D_{v} \\ \frac{1}{M} p(t) & |p(t)| \geq D_{v}\end{cases}
$$

The friction law is described as follows:

$$
\begin{aligned}
& F_{m}\left(v(t), F_{a}(t)\right) \\
& = \begin{cases}-\operatorname{sgn}\left[F_{a}(t)\right] \max \left[\left|F_{a}(t)\right|,\left(F_{c}+F_{s}\right)\right] & |v(t)|<D_{v} \\
-\operatorname{sgn}[v(t)] F_{c}+F_{v} v(t) & |v(t)| \geq D_{v},\end{cases}
\end{aligned}
$$

where (19) includes static, coulomb, and viscous terms $F_{s}, F_{c}$, and $F_{v}$.

4.2. Performance Evaluation. In this study, both SILS and HILS were performed for a period of 10 seconds using RungeKutta solver with a fixed step size of 0.001 seconds. The model is evaluated with various inputs with two types of frequency which are 0.5 and 1.0 hertz. The purpose of this validation is to verify the capability of the pitman arm steering to follow desired steering correction response after implementation in heavy vehicle system. Four types of desired trajectories known as sine, square, sawtooth, and step inputs have been used to verify the performance of the actual and the validated model pitman arm steering as shown in Figures 13-21.

Figures 13 and 14 show the comparison of the desired sine input wheel angle compared with the SILS and HILS results with and without friction compensation. Both SILS and HILS results are able to follow the desired wheel angle. HILS with 


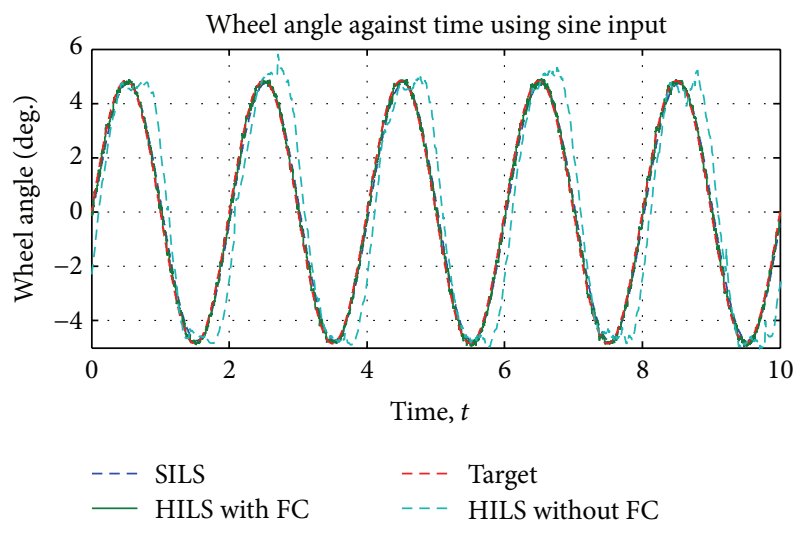

FIGURE 13: Wheel angle using sine input at $0.5 \mathrm{hz}$.

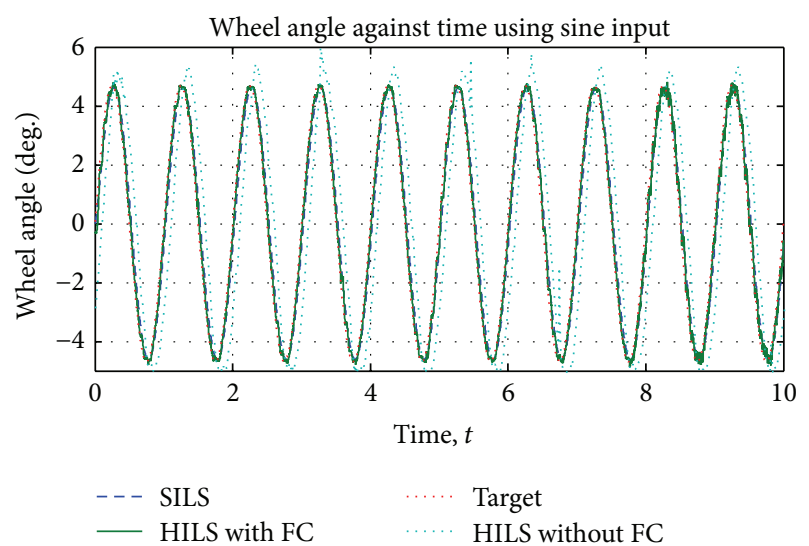

FIgURE 14: Wheel angle using sine input at $1.0 \mathrm{hz}$.

friction compensation follow the response without any influence from hardware but HILS without friction compensation follow the desired response with minor phase shifting due to mechanical response after experiencing friction between gears. It shows that friction compensation able to minimize the effect of the frictional force occurred in the hardware. The responses of the wheel angle for square inputs are shown in Figures 15 and 16 which illustrate minor deviation using HILS without friction compensation compared with simulation and HILS with friction compensation results. There is overshoot that occurred at each change point due to the backlash between gears of the DC motors. This interaction causes delay time up to 0.4 seconds as observed in the HILS results. By implementing the frictional compensation model, the overshoot in square response has been reduced significantly. Besides, the dead time that occurred during phase change has been minimized greatly compared with HILS without friction compensation response. Meanwhile, Figures 17 and 18 show the wheel angle using sawtooth inputs. The results show deviation during the middle of each period. This deviation mainly caused by the hardware interaction causes friction between connections of the pitman arm steering system and steering column which is attached to the hydraulic assist unit [19]. However, these minor deviations can be reduced by adding the friction compensation which estimated the

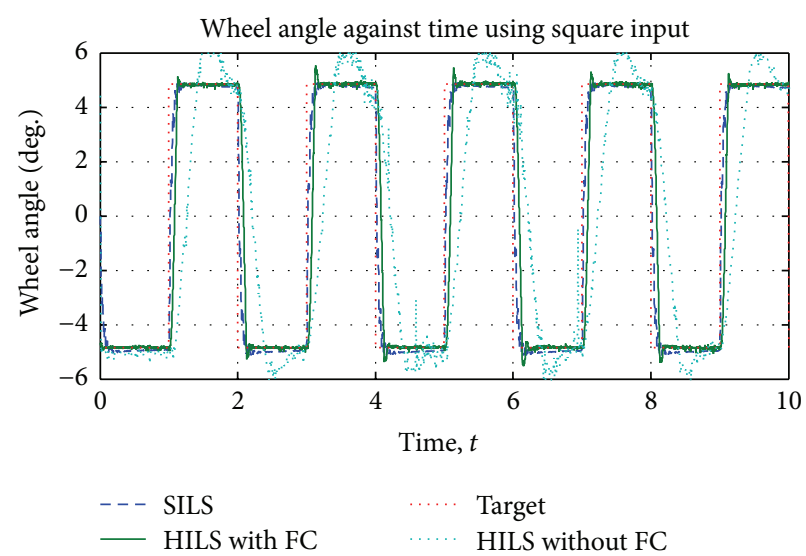

FIGURE 15: Wheel angle using square input at $0.5 \mathrm{hz}$.

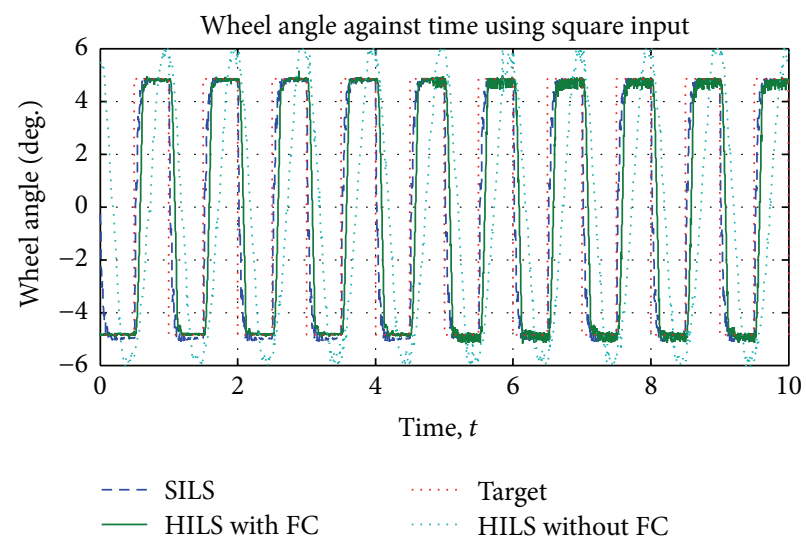

FIgURE 16: Wheel angle using square input at $1.0 \mathrm{hz}$.

friction that occurred and minimized the effects of unwanted friction.

Figures 19 and 20 represent the step response for HILS and SILS position tracking control using two desired wheel angles of $4.5^{\circ}$ and $9^{\circ}$. The HILS with friction compensation results show that the rise-time of step input of wheel angle at $4.5^{\circ}$ and $9^{\circ}$ is $3.07 \mathrm{~s}$ and $3.05 \mathrm{~s}$ at $10 \%$ height and at $90 \%$ of height is $3.45 \mathrm{~s}$ and $3.48 \mathrm{~s}$, while dead time occurs up to $0.08 \mathrm{~s}$ from rest condition in both cases. The maximum percentage of overshoot is up to $11.3 \%$ for wheel angle of $4.5^{\circ}$ and $10.2 \%$ for wheel angle of $9^{\circ}$ as shown in Figures 19 and 20. This minor deviation occurred due to sudden change in rotary sensors response and also because mechanical friction happened between the mounting and gear mechanism which connects DC motor and steering column. However, the HILS performance has been improved significantly by adding the friction compensation model in the HILS control structure which can be observed in Figures 19 and 20. Overall, the response of position tracking response of Pitman arm steering using automotive DC motor shows good agreement between desired trajectories, simulation, and actual response from validated and actual Pitman arm steering since the response of the actual response follows the desired input with a delay of less than $1 \mathrm{~s}$. 


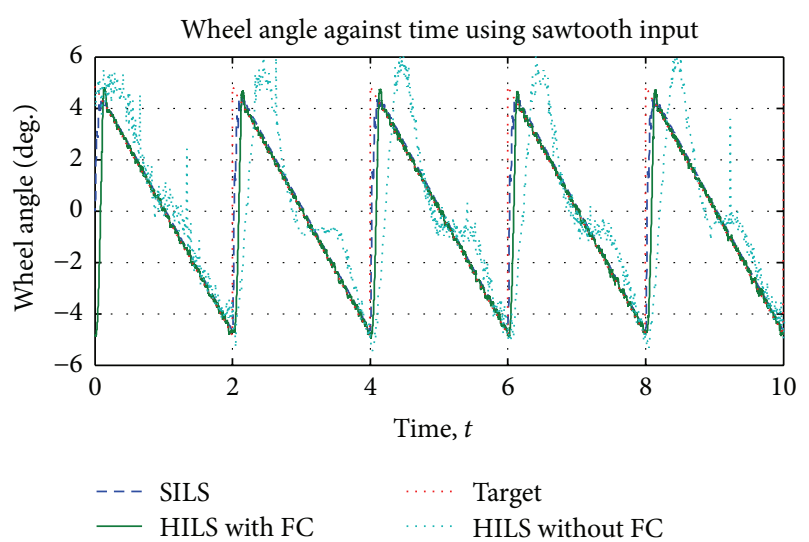

Figure 17: Wheel angle using sawtooth input at 0.5 hertz.

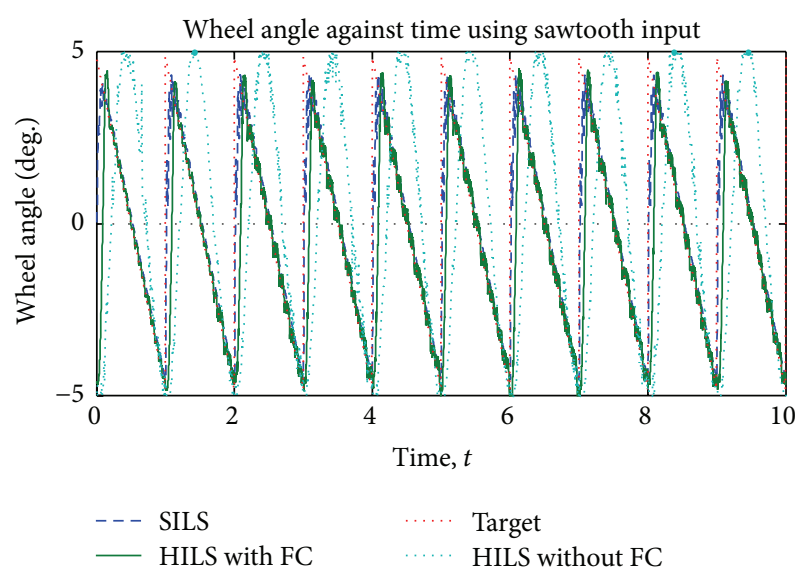

FIGURE 18: Wheel angle using sawtooth input at 1.0 hertz.

\section{Future Works}

Currently, this Pitman arm steering model is used as a firing-on-the-move actuator (FOMA) in the armored vehicle model. This active system is used mainly to reject the unwanted external disturbance due to backward firing momentum from the gun turret. The dynamic performance of the vehicle model with the pitman arm actuator system is analyzed in terms of yaw rate, lateral acceleration, and also vehicle body side slip. An advance control strategy is proposed to enhance the dynamic performance of the armored vehicle in terms of the directional path and stability of the armored vehicle after firing. The configuration of FOMA in armored vehicle is shown in Figure 21.

\section{Conclusions}

In this study, the Pitman arm steering system is developed using Newton's law motion to describe the working principle of the steering system. The Pitman arm steering model is then validated with an actual Pitman arm steering system in order to validate the mathematical model of the Pitman

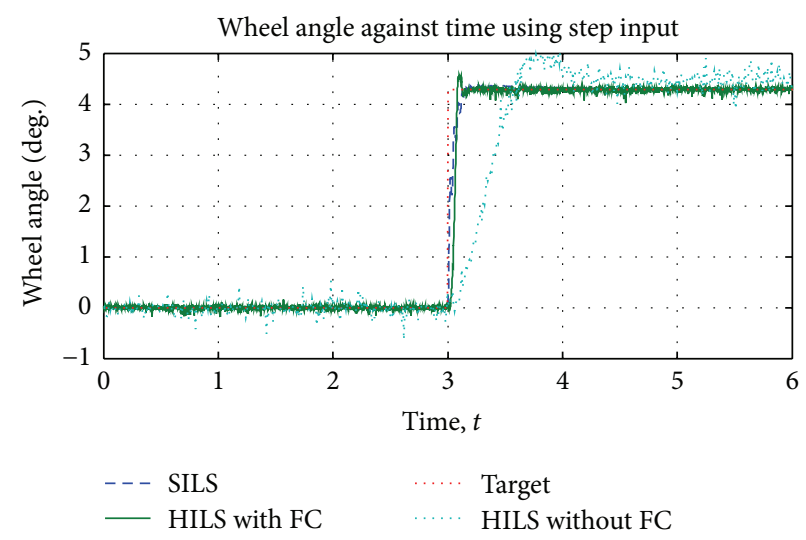

FIGURE 19: Wheel angle using step input response at 4.5 degree.

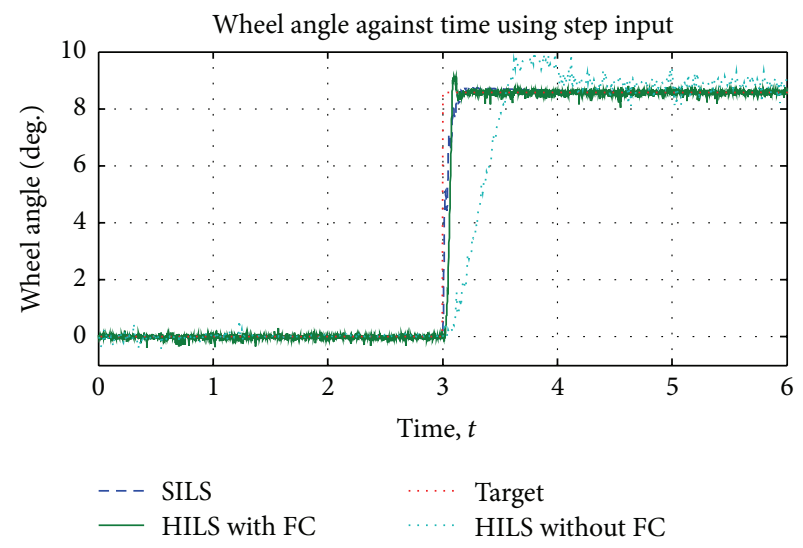

FIGURE 20: Wheel angle using step input response at 9 degree.

arm steering model. Four types of steering inputs in the lateral direction are used to evaluate the behavior of the developed steering model. Then, position tracking system using software-in-the-loop simulation (SILS) and hardware-in-theloop simulation (HILS) is developed using both validated and actual pitman arm steering system. Various types of desired inputs have been used to evaluate the performance of the validated and actual pitman arm steering system. In order to improve the HILS performance, friction compensation using Karnopp model is implemented in this study to minimize the effect of mechanical friction on the system. Significant improvement is obtained for the HILS results which is able to follow the desired response with errors less than $10 \%$. The position tracking system improved with friction compensation is used as inner loop model in the development of an active safety system in armored vehicle.

\section{Competing Interests}

The authors declare that there are no competing interests regarding the publication of this paper. 


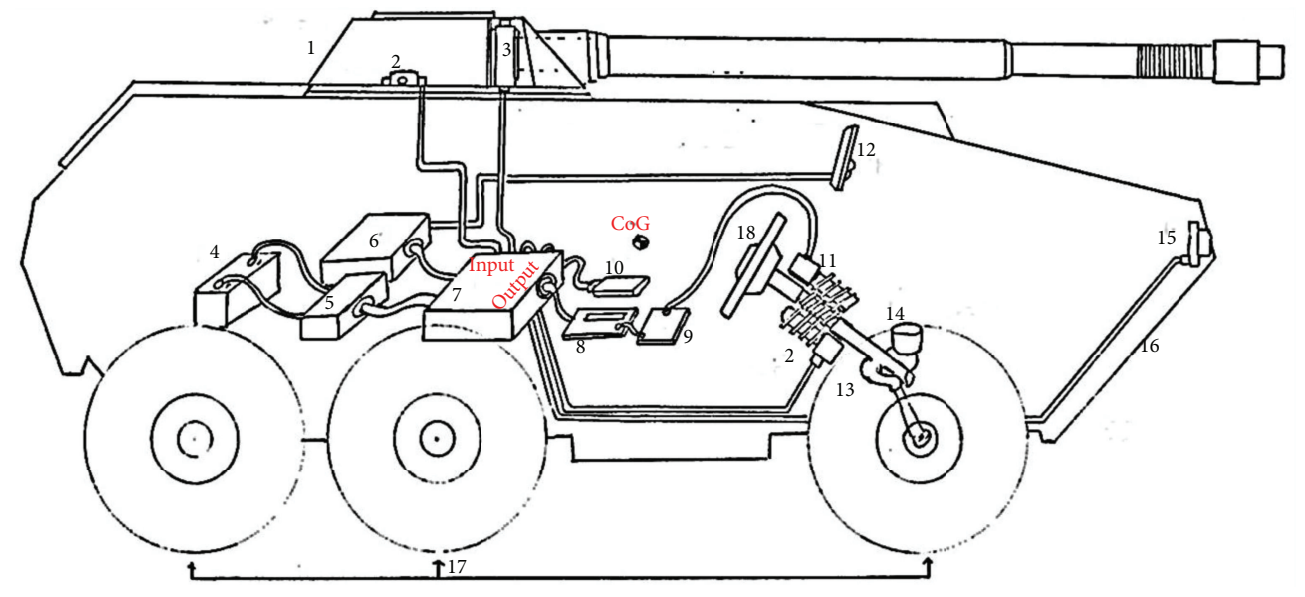
(1) Gun turret
(2) Rotary encoder
(3) Force sensor
(4) $12 \mathrm{~V}$ battery
(5) DC-AC converter
(6) Integrated PC based module
(7) Integrated DAQ
(8) Microcontroller
(9) Motor current driver

(10) Gyro sensor

(11) Brushless DC motor

(12) Touch screen LCD

(13) Pitman arm

(14) Hydraulic power assist

(15) Wheel speed sensor

(16) Vehicle body

(17) Wheel

(18) Steering

(a) Side view of armored vehicle

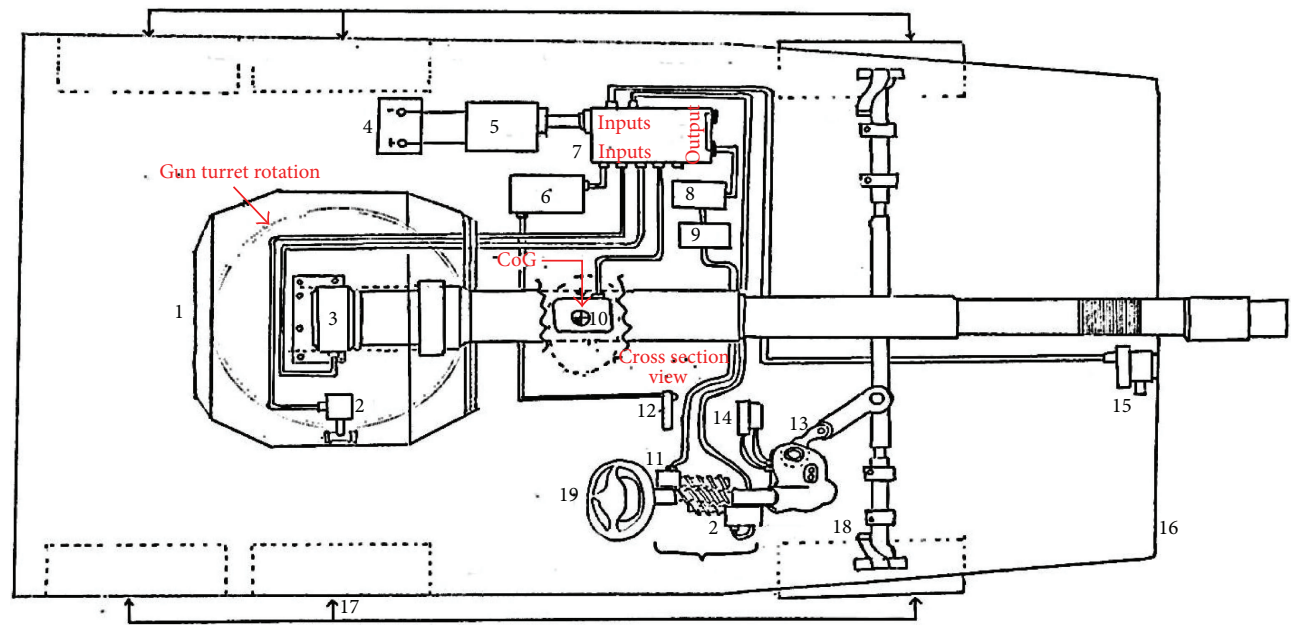
(1) Gun turret
(2) Rotary encoder
(3) Force sensor
(4) $12 \mathrm{~V}$ battery
(5) DC-AC converter
(6) Integrated PC based module
(7) Integrated DAQ
(8) Microcontroller
(9) Motor current driver

(10) Gyro sensor

(11) Brushless DC motor

(12) Touch screen LCD

(13) Pitman arm

(14) Hydraulic power assist

(15) Wheel speed sensor

(16) Vehicle body

(17) Wheel

(18) Knuckle

(b) Top view of armored vehicle

FIGURE 21: System configuration of electronically actuated Pitman arm steering system as firing-on-the-move actuator [23]. 


\section{Acknowledgments}

This work is part of a research project entitled "Robust Stabilization of Armored Vehicle Firing Dynamic Using Active Front Wheel Steering System," funded by LRGS Grant (no. LRGS/B-U/2013/UPNM/DEFENSE and SECURITY-P1) and led by Associate Professor Dr. Khisbullah Hudha. The authors would like to thank the Malaysian Ministry of Science, Technology and Innovation (MOSTI), MyPhD programme, from Minister of Education and National Defense University of Malaysia (NDUM) for their continuous support and the support is gratefully acknowledged.

\section{References}

[1] Z. Li and W. Wenjiang, "Study on stability of electric power steering system," in Proceedings of the IEEE International Conference on Robotics, Automation and Mechatronics (RAM '08), pp. 368-372, IEEE, Chengdu, China, September 2008.

[2] A. Marouf, C. Sentouh, M. Djemai, and P. Pudlo, "Control of an electric power assisted steering system using reference model," in Proceedings of the 50th IEEE Conference on Decision and Control and European Control Conference (CDC-ECC '11), pp. 6684-6690, IEEE, Orlando, Fla, USA, December 2011.

[3] L. Dong, K. Prasanth, G. Zhiqiang, and W. Dexin, "Active disturbance rejection control for an electric power assist steering system," International Journal of Intelligent Control and System, vol. 15, no. 1, pp. 18-24, 2010.

[4] P. Koehn and M. Eckrich, "Active steering-the BMW approach towards modern steering technology," SAE Technical Paper 2004-01-1105, 2004.

[5] W. Oraby, S. El-Demerdash, A. Selim, A. Faizz, and D. A. Crolla, "Improvement of vehicle lateral dynamics by active front steering control," SAE Technical Paper 2004-01-2081, SAE International, 2004.

[6] L. Dong, P. Kandula, Z. Gao, and D. Wang, "Active disturbance rejection control for an electric power assist steering system," International Journal of Intelligent Control and System, vol. 15, pp. 18-24, 2010.

[7] T. Kojo, M. Suzumura, Y. Tsuchiya, and Y. Hattori, "Development of active front steering control system," SAE Technical Paper 2005-01-0404, 2005.

[8] Y. Yao, "Vehicle steer-by-wire system control," SAE Technical Paper 2006-01-1175, SAE International, 2006.

[9] Y. Yao and B. Daugherty, "Control method of dual motor-based steer-by-wire system," SAE Technical Paper 2007-01-1149, SAE International, 2007.

[10] J. Li, J. Feng, and F. Yu, "Study of vehicle yaw stability control based on hardware-in-the-loop simulation," SAE Technical Paper 2005-01-1845, SAE International, 2005.

[11] K. Hudha, M. H. Zakaria, and N. Tamaldin, "Hardware in the loop simulation of active front wheel steering control for yaw disturbance rejection," International Journal of Vehicle Safety, vol. 5, no. 4, pp. 356-373, 2011.

[12] H. Schuette and P. Waeltermann, "Hardware-in-the-loop testing of vehicle dynamics controllers-a technical survey," SAE Technical Paper 2005-01-1660, 2005.

[13] J. C. Gerdes, P. Yih, and K. Satyan, Safety Performance and Robustness of Heavy Vehicle AVCS, California PATH Program, 2002.
[14] A. Farazandeh, A. K. W. Ahmed, and S. Rakheja, "Performance Analysis of Active Independent Front Steering (AIFS) for commercial vehicles with greater lateral load shift propensity," SAE International Journal of Commercial Vehicles, vol. 6, no. 2, pp. 288-300, 2013.

[15] V. R. Aparow, K. Hudha, M. M. Hamdan, and S. Abdullah, "Study on dynamic performance of armoured vehicle in lateral direction due to firing impact," Journal of Advances in Military Technology, vol. 10, no. 2, pp. 5-20, 2015.

[16] D. Karnopp, R. Argolis, and R. Rosenberg, System Dynamis: Modeling and Simulations of Mechatronic Systems, John Wiley \& Sons, New York, NY, USA, 2000.

[17] G. N. Shwetha, H. R. Ramesh, and S. R. Shankapal, "Modeling, simulation and implementation of a proportional-derivative controlled column-type EPS," International Journal of Enhanced Research in Science Technology and Engineering, vol. 2, no. 9, pp. 10-19, 2013.

[18] V. R. Aparow, K. Hudha, F. Ahmad, and H. Jamaluddin, "Modeling and validation of electronic wedge brake mechanism for vehicle safety system," Jurnal Teknologi, vol. 75, no. 1, pp. 183191, 2015.

[19] V. R. Aparow, K. Hudha, F. Ahmad, and H. Jamaluddin, "Modelin-the-loop simulation of gap and torque tracking control using electronic wedge brake actuator," International Journal of Vehicle Safety, vol. 7, no. 3-4, pp. 390-408, 2014.

[20] M. S. Saad, H. Jamaluddin, and I. Z. M. Darus, "Implementation of PID controller tuning using differential evolution and genetic algorithms," International Journal of Innovative Computing, Information and Control, vol. 8, no. 11, pp. 7761-7779, 2012.

[21] P. M. Meshram and R. G. Kanojiya, “Tuning of PID controller using Ziegler-Nichols method for speed control of DC motor," in Proceedings of the 1st International Conference on Advances in Engineering, Science and Management (ICAESM '12), pp. 117122, Tamil Nadu, India, March 2012.

[22] A. Voda and L. Ravanbod-Shirazi, "High performance position tracking with friction compensation for an electro-pneumatical actuator," Journal of Control Engineering and Applied Informatics, vol. 6, no. 2, pp. 15-33, 2004.

[23] K. Hudha, V. R. Aparow, M. Murad et al., "Yaw stability control system," Malaysian Patent PI 2015700778, October 2014. 


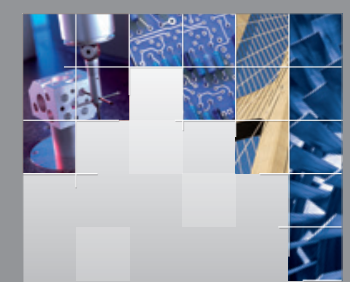

\section{Enfincering}
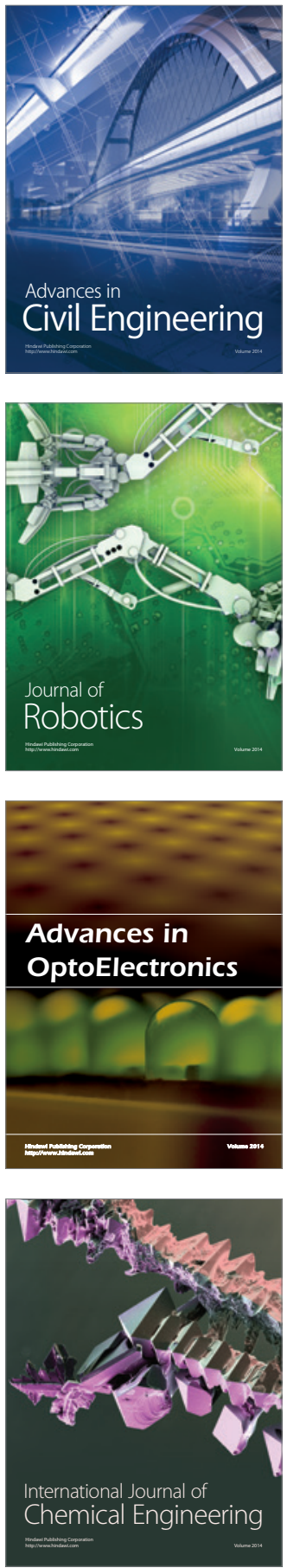

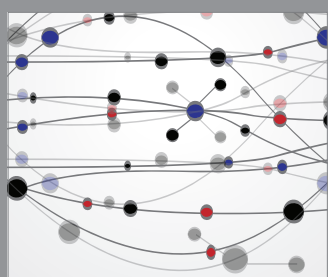

The Scientific World Journal

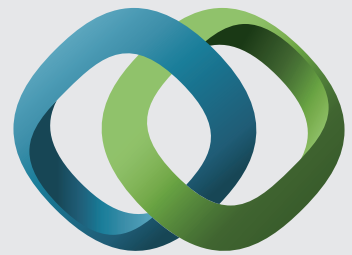

\section{Hindawi}

Submit your manuscripts at

http://www.hindawi.com
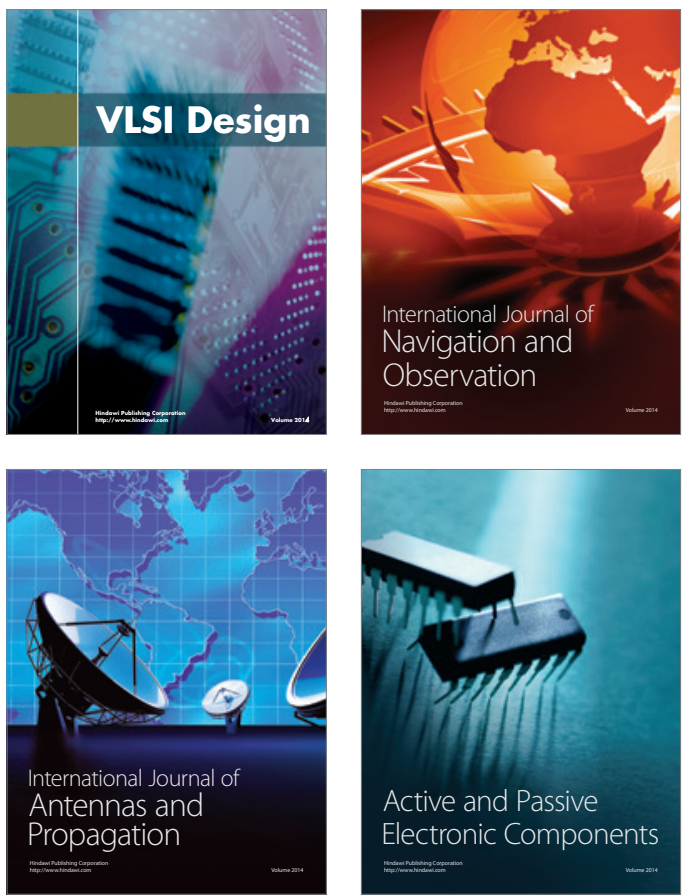
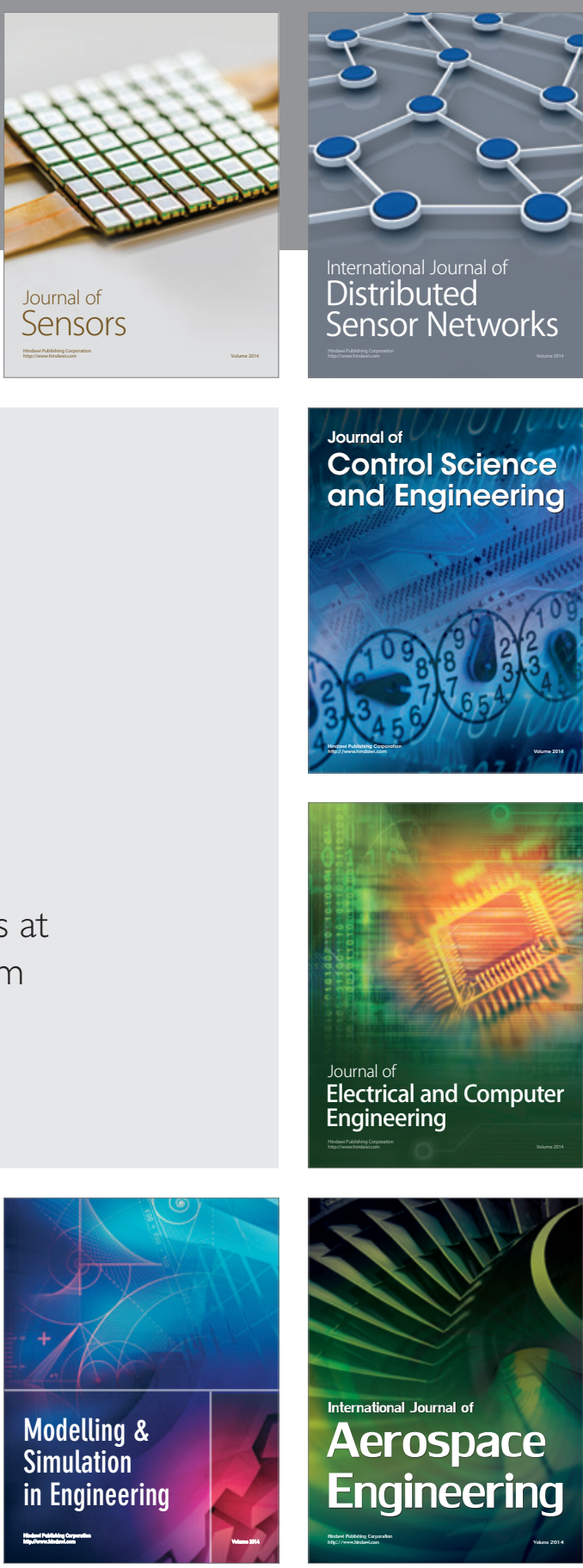

International Journal of

Distributed

Sensor Networks

Journal of

Control Science

and Engineering
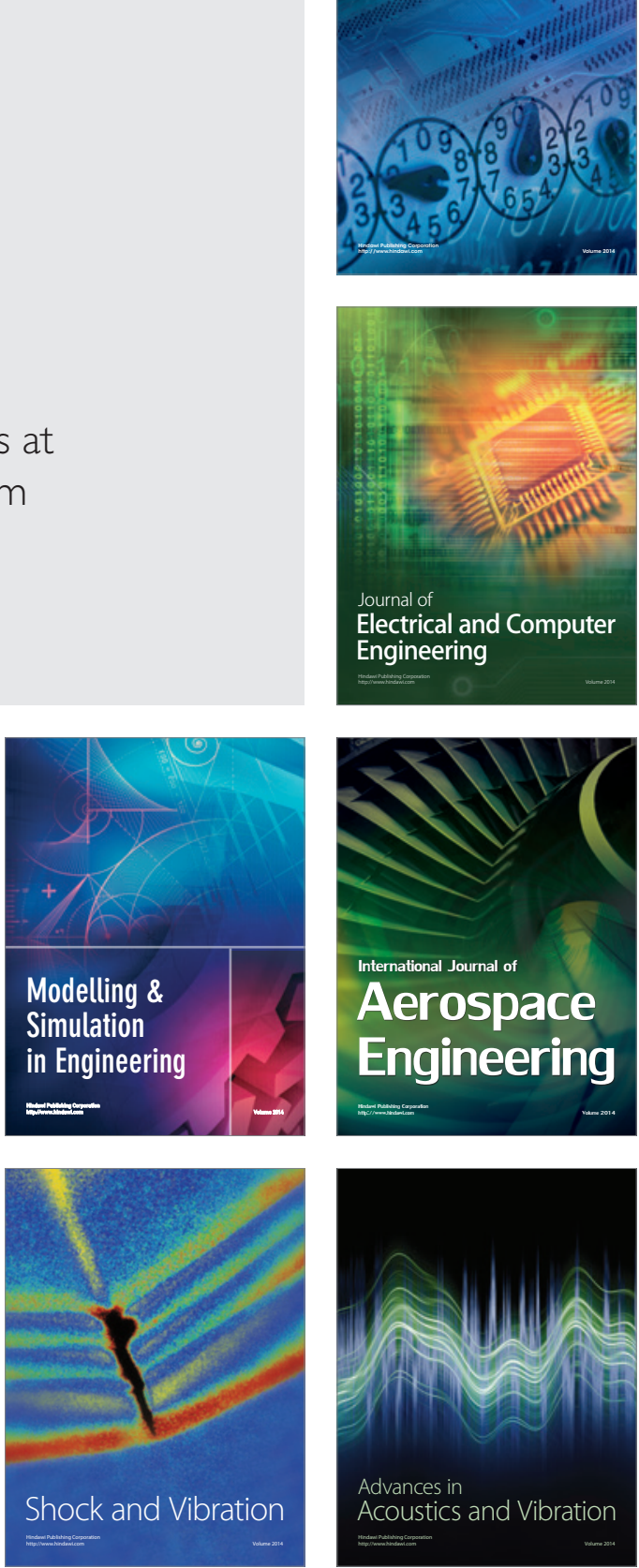